\title{
Transformasi Pengajaran dan Pembelajaran Multimedia dalam Pendidikan Islam: Satu Perbincangan
}

\author{
Transformation of Multimedia Teaching and Learning in Islamic Education: \\ A Discussion
}

\author{
Muhammad Zulazizi Mohd Nawi ${ }^{1 *}$ \\ ${ }^{1}$ Universiti Pendidikan Sultan Idris; zulazizi0902@gmail.com
}

* Corresponding author

To cite this article (APA): Nawi, M. Z. M. (2020). Transformasi pengajaran dan pembelajaran multimedia dalam pendidikan Islam: Satu perbincangan. Journal of ICT in Education, 7(2), 14-26. https://doi.org/10.37134/jictie.vol7.2.2.2020

To link to this article: https://doi.org/10.37134/jictie.vol7.2.2.2020

\begin{abstract}
Abstrak
Artikel ini membincangkan satu kajian yang menelusuri transformasi pengajaran dan pembelajaran melalui teknologi multimedia bagi memastikannya menjadi agenda utama dalam pendidikan Islam. Keperluan ini wujud disebabkan pendekatan yang dibawa ialah signifikan dan sesuai dilakukan selaras dengan Pendidikan Abad Ke-21 (PAK21) yang banyak memfokuskan pembinaan kemahirankemahiran yang meliputi kemahiran berkomunikasi, kemahiran 4M (membaca, mengira, menulis dan menaakul), kemahiran sains dan reka bentuk teknologi, kemahiran interpersonal dan intrapersonal dan lain-lain lagi secara syumul. Pendekatan sebegini juga dipercayai dapat memberikan peluang kepada para pelajar untuk mempelajari pendidikan Islam dengan lebih komprehensif. Justeru, diharapkan guru juga dapat menjadi peneraju perubahan, pemikir holistik serta pemangkin kepada kejayaan sistem pendidikan negara ini selain dapat memainkan peranan penting dalam membimbing pelajar supaya penglibatan pelajar dalam aktiviti pembelajaran dapat ditingkatkan.
\end{abstract}

Kata Kunci: teknologi multimedia, transformasi, pengajaran dan pembelajaran, pendidikan Islam.

\section{Abstract}

This article discusses a study that explores the transformation of teaching and learning approaches through multimedia technology to ensure that it is the main agenda in Islamic education. This need exists because the approach taken is significant and appropriate in line with 21st Century Education (PAK21) which focuses on building skills including communication skills, 4M skills (reading, counting, writing, and reasoning), science skill and design technology skill, interpersonal and intrapersonal skills and so on. This approach is also believed to provide opportunities for students to study Islamic education more comprehensively. Hopefully, teachers can also be leaders in change, holistic thinkers, and catalyst for the success of the country's education system besides playing a key role in guiding students to increase student engagement in learning activities.

Keywords: multimedia technology, transformation, teaching and learning, Islamic education. 


\section{PENGENALAN}

Dalam keghairahan merealisasikan pendidikan kelas pertama di dunia, bidang pendidikan khususnya di negara kita terus berhadapan dengan pelbagai cabaran dan transformasi dari semasa ke semasa. Pedagogi pengajaran yang berkesan boleh tercapai jika sistem pendidikan menfokuskan percambahan minda kritis dan lateral para pelajar dengan tidak menjadikan mereka sebagai tikus uji kaji. Antara skop Pembelajaran Abad Ke-21 (PAK21) yang acapkali digunapakai oleh guru seperti teknik perbincangan, tunjuk cara, simulasi, perbentangan, didik hibur dan sebagainya. Sayugianya, kesediaan guru dalam menggabungjalinkan sumber Bahan Bantu Mengajar (BBM) serta Pembelajaran dan Pemudahcaraan $(\mathrm{PdPc})$ dalam pengajaran ialah bergantung kepada transformasi multimedia dalam dunia hari ini yang boleh dimilikinya. Seseorang guru yang berwibawa dan peka terhadap transformasi akan cuba menarik minat pelajar dengan kaedah pengajaran yang popular dan kreatif merangkumi eksplorasi teknologi multimedia yang relevan dengan dasar keterbukaan Kementerian Pendidikan Malaysia (KPM).

\section{IMPLIMENTASI MULTIMEDIA DALAM PENDIDIKAN}

Multimedia mempunyai konsep yang sangat luas. Hari ini, multimedia diibaratkan sebagai medan utama untuk berkongsi maklumat daripada individu kepada individu yang lain yang sangat memerlukan maklumat daripada sesuatu maklumat yang mewakili kawasan tersebut ( $\mathrm{Hj}$ Mak Din et al., 2014). Ini bermakna dalam elemen multimedia sendiri, berlaku aktiviti komunikasi dua hala. Pada zaman kini, penggunaan multimedia bukan sekadar untuk berhibur sahaja, bahkan multimedia turut memainkan peranan yang sangat signifikan dalam bidang perniagaan, pentadbiran dan juga pendidikan (Abdul Talib, et al., 2019). Multimedia dalam Pengajaran dan Pembelajaran (PdP) adalah satu reka bentuk mesej atau komunikasi yang mengaplikasikan penggunaan teknologi canggih. Bahan pengajaran dan pembelajaran yang disampaikan melalui media mempunyai elemen-elemen multimedia seperti teks, grafik, animasi, simulasi, audio dan video (Putra, 2018). Multimedia dalam pendidikan juga mempunyai kategori yang dinamakan sebagai multimedia pengajaran, multimedia pembelajaran, multimedia pentaksiran, multimedia penilaian dan mempunyai tiga ciri-ciri utama iaitu (Dale, 1946):

1. Proses abstrak (unseen process)

2. Proses melihat (observation process)

3. Proses pengaruh (regression process)

Bertitik tolak daripada itu, pelajar akan mengoptimumkan lebih daripada satu deria semasa aktiviti pembelajaran seperti melihat, mendengar dan menyentuh lalu menghasilkan satu pengalaman, sikap, kemahiran serta ilmu (Rosni, 2000; Gan et al., 2015). Secara umumnya, Singh (2003) dalam kajian Ishak et al. (2009) menyatakan bahawa, pengajaran berasaskan multimedia adalah bersesuaian:

1. Jika pelajar mempunyai ilmu, pemikiran dan prestasi pembelajaran yang rendah, maka mereka memerlukan medium untuk merangsang kognitif agar dapat menghubungkannya dengan ilmu. 
Multimedia akan bertindak untuk menghasilkan sesuatu yang bermanfaat dalam menggambarkan aktiviti pembelajaran.

2. Jika pelajar mempunyai kecerdasan motivasi yang rendah. Kecerdasan motivasi sangat penting kerana mempengaruhi kawalan emosi diri, kemampuan berkomunikasi dan kemampuan berkerjasama sesama sendiri. Penggunaan elemen-elemen multimedia menjadi suatu medium penting kerana boleh membantu mereka untuk mewujudkan suasana pembelajaran kondusif. Bagi pelajar yang mempunyai kecerdasan motivasi yang baik, mereka tidak memerlukan bantuan daripada elemen-elemen multimedia secara total bagi membolehkan mereka belajar, tetapi mencukupi sekiranya dapat membantu mereka untuk memahami sesuatu yang baharu dalam PdP.

Antara media yang diklasifikasikan oleh Rudi Bretz adalah melibatkan tiga kriteria iaitu suara yang keluar dari sesuatu alat (audio), pergerakan yang dihasilkan (tindak balas) dan sesuatu dimensi yang dapat dilihat (visual) (Wibawanto, 2017). Elemen bunyi adalah elemen yang terhasil daripada getaran molekul di dalam jirim udara manakala elemen paparan bergerak adalah elemen yang mempunyai imej statik realistik. Elemen paparan bergerak yang terdiri daripada grafik (ilustrasi bergerak yang menarik), warna, audio dan visual yang membentuk gabungan harmoni dalam sesuatu perisian. Manakala antara lapan jenis media audio dan visual yang telah dikelaskan secara khusus oleh Fitra dan Andrijanto (2013) iaitu:

1. Media audio visual realistik bersifat media gabungan yang paling banyak dan lengkap yang membolehkan pelajar-pelajar menerima maklumat dengan efektif serta sistematik. Contohnya filem dari panggung wayang, gambar dan perkataan atau koswer multimedia, VCD atau DVD, telesidang, televisyen, projektor dan sebagainya.

2. Media audio visual statik ialah paparan media berupa imej, grafik yang menampilkan maklumat dan disertai dengan muzik sebagai latar belakang. Misalnya projektor lutsinar, slaid dan projektor slaid.

3. Media audio semi realistik hanya meletakkan maklumat, bunyi dan gerakan selari tanpa paparan visual yang estetik.

4. Media visual realistik hanya memaparkan maklumat dalam bentuk kombinasi animasi, imej, teks, dan tanpa suara.

5. Media visual statik pula memaparkan maklumat dalam bentuk kombinasi gambar, teks tanpa gerakan mahupun suara.

6. Media semi realistik meletakkan maklumat dalam bentuk separa gerak tanpa bunyi dan paparan visual.

7. Media audio adalah suatu medium pengantara (alat) yang hanya boleh didengari melalui telinga.

8. Media cetak merupakan satu wahana am yang meliputi teks, grafik, imej dan fotografik tanpa disertai paparan visual (video) dan audio. Kesemuanya digunakan untuk menyampaikan maklumat kepada pengguna.

\section{Multimedia sebagai Fokus Kognitif}

Kemahiran kognitif merujuk kepada tahap keupayaan intelek individu dalam memahami, mengingati, berfikir dan mengeluarkan pendapat terhadap perkara yang berlaku (Hamzah, Samuel, \& Kastawi, 2008). Bagi Wan \& Yunus (2017), kemahiran kognitif penting untuk meningkatkan konsistensi seseorang kerana ianya melibatkan aktiviti mental seperti mengingat, mengkategori, merancang, 
menaakul, menyelesaikan masalah, mencipta dan berimaginasi. Berdasarkan mazhab kognitivisme, seseorang manusia akan diuji berdasarkan potensi pemikiran di samping keupayaan mengelola, menyusun, menganalisis, menyimpan serta mengeluarkan maklumat daripada otak (Cooper, 1998). Sebelum data-data disimpan dalam ingatan jangka Panjang (long-term memory), data-data tersebut akan dikodkan secara sementara di dalam saraf pusat memori (centre memory cord) sehingga tempoh 15 saat.

Persembahan multimedia turut mempengaruhi pencapaian akademik pelajar (Said et al., 2015). Hal ini disebabkan anjakan penggunaan Alat Bahan Bantu Mengajar (AABM) yang dibina berasaskan perisian multimedia seperti mobil, koswer serta pembelajaran permainan (Khairuddin \& Mailok, 2020). Pembangunan perisian berasaskan multimedia telah memberi peluang kepada pelajar untuk bebas mengawal pembelajaran dengan lebih baik melalui peluang pembelajaran secara kerjasama, interaktif atau persendirian. Pelajar boleh menentukan masa, isi kandungan, iklim, cadangan aktiviti dan maklumat yang disukai berpandukan silibus bagi sesuatu mata pelajaran. Pentaksiran akan berlaku berdasarkan elemen sifat, kekuatan, kelemahan prestasi, bakat serta corak pembelajaran pelajar. Persembahan animasi dan narasi dalam multimedia sebagai contohnya sangat menghiburkan serta tidak membosankan kerana dapat menggerakkan saluran verbal dan visual di dalam memori secara berkesan (Basri \& Lakulu, 2018; Wilson et al., 2015) di samping dapat membentuk pembelajaran aktif seiring dengan kedinamikan interaktiviti yang berlaku antara pengguna dengan elemen multimedia tersebut (Zaibon, 2015). Tidak dapat dinafikan, pelbagai kemudahan yang disediakan dalam multimedia sama ada berbentuk pembelajaran pantas ataupun pembelajaran sambil menikmati keseronokan bermain (Alimom \& Mohd Azlan, 2019; Jamaludin \& Tasir, 2001). Tambah Ismail (2010) pula, walaupun ramai pelajar menyukai dan sangat seronok dengan pembelajaran menggunakan elemen-elemen multimedia, namun aktiviti pengayaan pembelajaran berasaskan elemen-elemen multimedia yang melampau juga akan turut memberikan kesan yang buruk terhadap proses PdP (MdSharif, 2012).

\section{SENARAI LITERASI MULTIMEDIA DALAM PENGAJARAN DAN PEMBELAJARAN}

Perkembangan arena teknologi berasaskan multimedia dalam PdP memerlukan perubahan yang holistik dalam pelbagai aspek, termasuk perbezaan perspektif dalam kalangan pendidik bagi membolehkan mereka menyusun semula peranan masing-masing agar keperluan kualiti pendidikan dapat dipenuhi dan mencapai standard satu pertiga teratas dalam kalangan negara yang mempunyai sistem pendidikan terbaik di dunia menjelang tahun 2050. Revolusi drastik terhadap teknologi digital berasaskan multimedia buat masa ini, dapat memberikan dorongan kepada para guru untuk lebih futuristik dalam mencorak sahsiah kepada anak didik sejajar dengan sikap kebertanggungjawaban menyalurkan ilmu kepada mereka. Bagi menggapai refleksi PdP yang holistik, para guru perlu merancang, bersedia dan mengatur pelan pengajaran yang merangkumi struktur serta latihan yang lebih sistematik bagi aktiviti di dalam bilik darjah sebelum proses pembelajaran bermula. Adapun sumber terbaik bagi membina kemahiran komunikasi interaktif, kemahiran berfikiran kritis dan kemahiran pencarian maklumat aktif adalah menerusi empat bentuk teknologi era digital iaitu: 


\section{PdP Berasaskan Multimedia dalam Talian}

Pembelajaran multimedia dalam talian adalah satu bentuk komunikasi yang dibina bagi memberikan kelangsungan interaksi dalam kalangan komuniti maya. Misalnya platform EPSA, Coursera, EDX, FutureLearn dan sebagainya. Persediaan PdP berasaskan pembelajaran multimedia dalam talian dengan bantuan aplikasi pelantar yang fleksibel untuk para pelajar dan guru, mampu memenuhi strategi PdP yang bervariasi dan boleh menggantikan buku atau sumber PdP secara bersemuka selain menggalakkan penerapan kemahiran mengakses maklumat dan bahan di mana sahaja yang dirasakan selesa (All, Nuñez Castellar, \& Van Looy, 2016; Aytekin Isman et al. 2015; Rahman et al., 2014; Rahman et al., 2011). Implikasi daripada itu, berlaku kerjasama antara pelajar dengan guru. Hasilnya juga boleh mewujudkan pengajaran berpusatkan pelajar, membina persekitaran yang mesra, menggalakkan pelajar untuk memberi maklum balas yang kritikal, memberi rujukan penempatan pelajar yang lain, meningkatkan kemahiran menulis, berdialog, motivasi dan keyakinan para pelajar dalam pembelajaran masing-masing (Munusamy \& Mohamad Yatim, 2017; Isman, Aydin \& Simsek, 2015).

Dari sudut motivasi, para pelajar akan terus bersemangat untuk melakukan aktiviti perbincangan dalam talian kerana jadual pembelajarannya yang fleksibel dan aspek literasi ilmu yang boleh dimanfaatkan (Aina, 2013). Bagi perkara melibatkan penguasaan silibus PdP pula, para pelajar dan guru perlu bersedia dengan topik santai dalam sesuatu perbincangan tanpa terlalu kaku, terkurung dan jumud dengan penetapan pelan pengajaran. Justeru, apabila melibatkan perbincangan dalam lingkungan komuniti maya, maka sudah pasti secara tidak langsung dapat mencuri tumpuan masing-masing mengenai konteks PdP yang dilakukan. Para pelajar juga secara tidak langsung dapat meningkatkan tahap Kemahiran Berfikir Aras Tinggi (KBAT), menambah keyakinan, berkongsi pengalaman dan menimba ilmu baharu serta membina rangkaian berkolaboratif dalam kalangan komuniti maya tanpa rasa tertekan mengikut domain perbincangan yang dibuat.

\section{PdP Berasaskan Multimedia Hibrid}

Pembelajaran Multimedia Hibrid adalah pembelajaran berpusatkan pelajar yang memberikan penekanan kepada pembinaan kemahiran seseorang pelajar melalui sokongan pengintegrasian teknologi Web 2.0, rangkaian sosial serta interaktif yang meluas (Adzhar, Abdul Karim \& Sahrin, 2017). Pembelajaran Hibrid boleh menjadikan pembelajaran makin menarik apabila ditambah dengan penggunaan media sosial (YouTube, QQ, WeChat, WhatsApp, Instagram, Facebook, Qzone, Sina Weibo atau Reddit), teknologi koswer (telesidang audio, video, telesidang komputer, internet atau mel elektronik), animasi 2D, 3D, 4D, 5D atau 6D serta Realiti Maya (secara desktop). Dalam pengajian di Sekolah Menengah Kebangsaan Harian (SMK) atau Sekolah Berasrama Penuh (SBP) atau Sekolah Bestari (SB), konsep Pembelajaran Hibrid turut juga diterapkan bagi menggalakan fokus pelajar terhadap gaya pedagogi guru, gaya pembelajaran, aktiviti dan penilaian bilik darjah melalui pendekatan pembelajaran abad ke-21. Ianya juga merupakan suatu kombinasi antara pola pembelajaran secara mod atas talian (online) dengan pembelajaran bersemuka mod onsite dan keadaan 
ini dapat mewujudkan satu kaedah persekitaran pembelajaran yang berkolaboratif (Hussin, et al., 2013).

\section{PdP Berasaskan Multimedia Konvergen}

Pembelajaran multimedia konvergen merupakan satu pendekatan yang menerapkan penggunaan Teknologi Maklumat dan Komunikasi (TMK) dalam bidang pendidikan terutamanya dalam konteks pengajaran dan pembelajaran (PdP). Pada hari ini, e-pembelajaran berlaku melalui kemudahan infrastruktur dan infostruktur yang saling memerlukan, kegagalan salah satu akan menyebabkan proses PdP dalam talian tidak dapat dilakukan dengan baik. Pada masa yang sama, KPM juga turut menyediakan pelbagai kursus bagi membolehkan para guru menerima bimbingan, latihan dan kemahiran yang mencukupi. Menurut Penerima Anugerah Guru Cemerlang Kementerian Pendidikan Malaysia (KPM), Anuar Ahmad, cabaran norma baharu (new norm) pada era Perintah Kawalan Pergerakan (PKP) dan penularan wabak Covid-19 menyaksikan satu senario besar dalam transformasi e-pembelajaran dan kebanyakan guru terpaksa menghadapinya dengan tangan terbuka (Berita Harian, 2020).

Namun, perkara ini tidak menjadi halangan kerana terdapat kumpulan guru yang pakar dalam penggunaan e-pembelajaran seperti CikgooTube, kumpulan Telegram, Google Classroom Malaysia, Facebook Guru Perpustakaan dan Media yang bersedia untuk membantu rakan guru jika memerlukan. Secara umumnya, pembelajaran multimedia konvergen dilengkapi dengan kriteria multimedia seperti audio, visual dan mempunyai capaian bagi bimbingan secara menyeluruh. Pembelajaran multimedia konvergen bukan sahaja melibatkan penggunaan aksesori atau gajet seperti komputer riba, e-reader atau tablet, ipad, iphone, telefon pintar tetapi turut melibatkan pelbagai pelantar pembelajaran digital yang lain seperti Skype, Zoom, Webex, Schoology, Google Classroom, Green Screen, Edpuzzle, Cidos e-learning portal, Microsoft Teams, editor video (Youtube Editor atau VivaVideo), aplikasi latihan dalam talian dan EduwebTV.

Pembelajaran multimedia konvergen juga adalah satu jaringan yang bukan sahaja melibatkan akses memuat naik, menyimpan dan menghantar kandungan pembelajaran tetapi melibatkan pemudahcaraan secara e-pembelajaran (Eldy \& Sulaiman, 2015). Dengan ciri-ciri menarik yang ada pada pembelajaran multimedia konvergen serta minat para pelajar terhadap fungsi-fungsi aplikasi teknologi yang berasaskan web, e-pembelajaran juga dianggap berbaloi digunakan kerana boleh menjimatkan kos, jurang masa, tenaga dan jarak yang menjadi halangan untuk belajar (Adzhar, Abdul Karim \& Sahrin, 2017). Selain itu, penggunaan pembelajaran multimedia konvergen sememangnya lebih fleksibel kerana memudahkan perkongsian kandungan pembelajaran, melancarkan komunikasi jarak jauh dan meningkatkan pengalaman eksplorasi individualistik secara serentak (Kassim \& Abdul Razaq, 2010). 


\section{PdP Berasaskan Multimedia Secara Pendidikan Jarak Jauh (Distance Education)}

Pada zaman pendidikan digital yang semakin mencabar ini, ilmu pengetahuan memainkan peranan yang penting dalam meningkatkan mutu kehidupan dan telah menuntut setiap negara untuk "berdiri sama tinggi, duduk sama rendah" dalam setiap bentuk pembangunan pendidikan masing-masing. Di negara maju, istilah pendidikan jarak jauh (distance education) bukanlah satu perkara yang baharu. Sistem pendidikan jarak jauh yang ditubuhkan sekarang ini merupakan salah satu agen sosialisasi terbaik dari abad ke-20 hingga abad ke-21 yang diterima dan diakui di seluruh dunia kerana memperkasakan konsep pembelajaran sepanjang hayat (lifelong learning) kepada para pelajar yang tidak perlu berada di satu lokasi setempat. Berbeza dengan konsep pendidikan konvensional di mana guru boleh menerapkan kaedah pendidikan jarak jauh berkonsepkan forum, bengkel, kursus, seminar atau sebarang program yang bersinergi dan komprehensif bagi menambahkan pengalaman mereka. Dulu penyampaian pengajaran dan pelajar menyalin nota di papan putih. Kini, sistem pendidikan jarak jauh menggunakan pengantaraan terbuka bagi mempersembahkan bahan pembelajaran kepada para pelajar.

\section{MULTIMEDIA MENURUT ISLAM}

Merujuk kepada peradaban awal Islam, teknologi bukanlah sesuatu yang baharu digunakan, tetapi merupakan suatu proses berterusan dan berkembang dalam kehidupan umat Islam sehingga menjadi pencetus dan penggerak utama kepada kejayaan membentuk sebuah tamadun yang hebat pada masa itu. Penerapan teknologi berasaskan multimedia ke dalam tasawwur Islam tidak menjadi simbolik kepada pengharaman kerana hukum asal bagi sesuatu yang membawa manfaat yang besar terhadap kemajuan manusia adalah harus. Perkara ini telah dinyatakan melalui penulisan yang dibuat oleh Martias (2010) bahawa, tiada dalil, nas (teks), 'talfiq baina mazahib' (cantuman mazhab) atau khilaf (perselisihan) antara para ulamak yang jelas menyatakan penggunaan teknologi multimedia ialah haram kerana Islam merupakan agama yang sentiasa menitikberatkan kemaslahatan umatnya agar selari dengan sesuatu perubahan dan perkembangan semasa. Islam juga menggesa umatnya supaya memberi penekanan terhadap penguasaan ilmu pengetahuan yang mencakupi pelbagai kombinasi dalam beberapa bidang yang lain termasuklah ilmu pengetahuan yang berhubung erat dengan teknologi berasaskan multimedia.

Sejarah juga telah membuktikan bahawa, umat Islam merupakan umat yang terbaik berbanding umatumat agama yang lain kerana berjaya mencipta salah satu eleman multimedia bagi tujuan penyebaran maklumat iaitu dengan memulakan media transmisi secara auditif (azan) pada tahun pertama Hijrah di Madinah berbanding orang Kristian yang pertama kali menggunakan media audio pada tahun 1837 (Osial Dan, 1989). Tambahan pula, menurut Osial Dan (1989) lagi, pada zaman permulaan Islam sejak 1500 tahun dahulu, sebahagian besar budaya masyarakat pada masa itu menggunakan sistem pindahan suara, tabuhan beduk serta tulisan di tempat umum (tembok, batu dan pohon) sebagai medium untuk menyampaikan sesuatu maklumat penting. Melalui sejarah ini, telah terbukti bahawa teknologi berasaskan multimedia telah lama wujud dalam kehidupan manusia. Walau bagaimanapun, 
penggunaan teknologi berasaskan multimedia masih bergantung kepada lunas-lunas perundangan Islam. Apatah lagi pemanfaatan daripada kemudahan ini yang digunakan dalam proses PdP telah dimanipulasikan oleh golongan tertentu tanpa batasan syarak. Oleh sebab itulah, umat Islam perlu sedar akan setiap fungsi media yang telah ada ini dengan memastikan penerapan multimedia secara Islamik sama ada di sekolah rendah mahupun di sekolah menengah perlulah berfikrah, bertepatan dan terancang bagi memastikan keberkesanan proses pengajaran dan pembelajaran (Mohid, et al., 2018).

\section{Keperluan Multimedia dalam Aktiviti PdP Pendidikan Islam}

Untuk kekal maju dalam persekitaran budaya berpengetahuan dan komunikasi di peringkat global, keperluan multimedia sebagai kuasa kawalan pembelajaran tidak boleh disisihkan oleh sektor pendidikan di mana-mana negara dalam dunia. Keunggulan memanfaatkan multimedia dalam pelbagai disiplin ilmu mampu melahirkan satu bentuk pendidikan yang lebih berkualiti dan bestari. Benarlah apa yang dinyatakan melalui penulisan Achmad Setiawan, Suryani \& Asrowi (2017) bahawa, sesebuah masyarakat dalam negara yang boleh menguasai dengan bijak teknologi berasaskan multimedia sama ada dalam bentuk penggunaannya untuk aktiviti harian mahupun dalam aspek penggunaan dalam aktiviti perkhidmatan seperti pendidikan, perniagaan, perdagangan, pelancongan, pengangkutan, utiliti keperluan asas dan sebagainya secara tidak langsung penduduk tersebut akan terkehadapan untuk menghadapi cabaran globalisasi yang berasakan ilmu dan kemahiran pemudahcaraan pada dekad akan datang.

Dalam lingkungan penggunaan multimedia pula, terdapat tiga jenis ruang lingkup multimedia yang menjadi aktiviti menapis, menyaring dan menentukan keutamaan maklumat dalam PdP bagi Pendidikan Islam (Koderi, 2015):

1. Ruang lingkup de facto prescriptive (bersifat memberi penjelasan) merupakan ruang lingkup multimedia asas yang boleh menentukan kolaborasi (tutorial) antara guru dengan pelajar dalam PdP bagi Pendidikan Islam. Sebagai contohnya games (permainan), simulasi dan pembelajaran drill.

2. Ruang lingkup democratically (secara bebas) adalah suatu ruang lingkup multimedia sederhana yang menggalakkan guru untuk mengawal aktiviti PdP bagi Pendidikan Islam dalam bilik darjah. Ianya juga terdiri daripada sumber dan pembelajaran tambahan.

3. Ruang lingkup cybernetics (sistem hubungan dan komunikasi) ialah ruang lingkup multimedia yang maju dan kebanyakkannya telah diamalkan oleh para guru di sekolah. Misalnya, sistem yang menggantikan sistem bercetak (printed system) kepada sistem tidak bercetak (non-printed system) atau sistem atas talian (online system).

\section{Hubungan Multimedia dengan Pendidikan Islam}

Terdapat berpuluh-puluh dalil dan keterangan ayat yang menghuraikan betapa eratnya hubungan antara al-Quran dengan teknologi berasaskan multimedia. Hakikatnya perkara ini bukanlah sesuatu yang pelik kerana semua ilmu yang ada di bumi, langit dan seluruh alam semesta itu ialah milik Allah s.w.t. Begitu juga dengan ilmu teknologi berasaskan multimedia turut berpunca daripada Allah s.w.t. 
Kenyataan ini boleh dibuktikan melalui kajian Ismail (1998) yang menyatakan bahawa, surah Al-'Alaq yang diturunkan kepada Nabi Muhammad s.a.w (lima ayat pertama dari surah ini) secara tidak langsung telah menghuraikan mengenai teknologi berasaskan multimedia:

\section{Bacalah (wahai Muhammad) dengan nama Tuhanmu yang telah menciptakan (sekalian makhluk). Dia telah menciptakan manusia dari sebuku darah. Bacalah dan Tuhanmulah Yang Maha Pemurah. Yang mengajar manusia melalui pena dan tulisan. Dia telah mengajarkan manusia apa yang tidak diketahuinya. \\ (Surah al-'Alaq: 1-5)}

Seperti yang telah disebutkan di dalam surah ini, Allah s.w.t telah menggunakan kalimah Iqra' (bacalah), Qalam (alat menulis), dan 'Allama (mengajar) bertujuan untuk memberi isyarat mengenai penghayatan sesuatu ilmu sehinggakan wujudlah penciptaan teknologi bagi membantu menyenangkan urusan manusia. Menurut Abdul Majeed \& Othman (1998), perisian atau teknologi yang muncul pada hari ini yang digunakan bagi menggantikan konsep "baca, pena dan ajar" adalah teknologi digital seperti penggunaan komputer, bahan elektronik, Liquid Crystal Display (LCD), kamera video digital dan lain-lain lagi. Apabila adanya teknologi ini penyampaian maklumat Pendidikan Islam akan menjadi lebih ideal dan tertumpu.

Dalam dunia yang penuh bergelora ini, ternyata sekali bahawa, mana-mana negara yang memiliki penguasaan dan kekuatan dalam teknologi berasaskan multimedia adalah dianggap sebagai negara yang paling dihormati dan mempunyai pengaruh yang besar kepada sistem komunikasi global, keadaan sosial sejagat, kuasa ekonomi antarabangsa, sektor perubatan moden, pendidikan dan sebagainya. Oleh sebab itulah, umat Islam perlu berusaha untuk menjadikan negara-negara mereka sebagai salah sebuah negara yang hebat dalam semua aspek dan berupaya menempuh gelombang perkembangan serta perubahan masa kini. Hal ini demikian kerana, apabila sesebuah negara yang dimiliki oleh umat Islam itu boleh menguasai segala bidang ilmu termasuk teknologi berasaskan multimedia maka usaha pendidikan Islam dan penyebaran dakwah Islamiyyah dapat dilakukan dengan berkesan tanpa dihalang oleh mana-mana negara yang menentang Islam (Suparman, et al., 2016).

\section{Strategi PdP Berasaskan Multimedia dalam Pendidikan Islam}

Pembelajaran dan Pengajaran (PdP) dalam pendidikan Islam hendaklah dilakukan oleh guru-guru Pendidikan Islam (GPI) sebagai kesinambungan di peringkat Kurikulum Standard Sekolah Rendah (KSSR) dan Kurikulum Standard Sekolah Menengah (KSSM) iaitu menggabungjalin perkara fardu ain dengan fardu kifayah. Sudah semestinya hal ini bertujuan untuk mendidik akal, jasmani dan roh manusia dengan nilai-nilai insaniah yang bersumberkan al-Quran dan as-Sunnah Nabawiyyah agar dapat memberikan sumbangan kepada agama, bangsa dan negara. Strategi penstrukturan penyampaian dan pengajaran GPI berasaskan multimedia perlu dilakukan supaya dapat mengikuti 'uruf (budaya) Pendidikan Islam yang sebenar, menjaga tradisi iklim pembelajaran Islam dengan pelbagai pendekatan dan menghuraikan secara holistik tentang pengajaran Pendidikan Islam yang melibatkan lima hukum 
utama iaitu wajib, sunat, harus, makruh dan haram supaya tidak timbul kesalahan penafsiran dalam kalangan pelajar (Yusopp, 2002).

Penggunaan teknologi berasaskan multimedia dalam pendidikan boleh dilihat berdasarkan dua perkara utama iaitu pengajaran yang melibatkan guru dan pembelajaran yang melibatkan pelajar sebagaimana yang digariskan oleh Unit Komputer dalam Pendidikan, Kementerian Pendidikan Malaysia (2001) adalah seperti pendekatan pembelajaran tutorial (kolaboratif), penerokaan (akses sendiri), kajian kes (pengaplikasian teori atau konsep terhadap situasi), alat aplikasi (penerapan kemahiran penggunaan perisian), dan alat komunikasi (koperatif). Dunn \& Dunn (1978) telah menegaskan bahawa, strategi penggunaan elemen multimedia dalam pengajaran sangat digalakkan terutama sekali bagi matapelajaran yang memerlukan pemahaman dan pembacaan yang mendalam sebagai contohnya mata pelajaran Pendidikan Islam. Syaibani (1997) pula menambah, strategi dalam proses pengajaran dan pembelajaran yang berkesan adalah merujuk kepada strategi pemusatan guru, strategi pemusatan pelajar, strategi pemusatan bahan dan strategi berasaskan tugasan.

Setiap strategi hendaklah mempunyai asas-asas perancangan, manhaj (metode) yang kukuh, mantap dan mencapai objektif jangka panjang selain dapat memenuhi keperluan pelajar untuk mempelajarinya sama ada di dalam atau di luar kelas seterusnya dapat melahirkan pelajar cemerlang (Ismail, Salleh \& Jemali, 2016).

\section{Kaedah PdP Berasaskan Multimedia dalam Pendidikan Islam}

Sebenarnya, Islam tidaklah melihat pendidikan dari perspektif yang sempit, juga tidak terbatas kepada pendidikan duniawi semata-mata bahkan meliputi dua lapangan iaitu di dunia dan akhirat. Allah s.w.t sendiri telah berfirman di dalam Surah al-Isra' ayat 1 yang bermaksud:

"Maha Suci Allah yang telah menjalankan hamba-Nya (Muhammad) pada malam hari dari Masjid Al-Haram (di Makkah) ke Masjid Al-Aqsa (di Jerusalem), yang Kami berkati sekelilingnya, untuk memperlihatkan kepadanya tanda-tanda (kekuasaan dan kebesaran) Kami. Sesungguhnya Allah jualah yang Maha Mendengar lagi Maha Mengetahui."

Berdasarkan firman Allah s.w.t di atas, ayat ini jelas menunjukkan tentang kronologi peristiwa yang berlaku atas diri Rasulullah s.a.w ketika mana baginda s.a.w dibawa mengembara dari satu tempat ke satu tempat yang mempunyai jarak yang jauh pada satu malam sahaja. Jika diteliti secara mendalam, peristiwa ini adalah ganjil dan sukar untuk dijelaskan kerana tak terjangkau dek akal manusia normal (H. Osman \& Nasir, 2011). Hal ini dapat disandarkan kepada beberapa gambaran pelik yang dipaparkan kepada baginda s.a.w menerusi pancainderanya kemudian ditafsirkan semula oleh Jibril a.s dengan kata lain keseluruhan pengembaraan baginda s.a.w ini adalah bertujuan untuk menunjukkan betapa tingginya darjat yang dianugerahkan oleh Allah s.w.t kepada baginda s.a.w. Ahmad Mohd Salleh (2008) seperti mana di dalam penulisan Kaimin \& Che Noh (2016) mengatakan bahawa, antara 
contoh kaedah PdP berasaskan elemen multimedia yang jelas dinyatakan daripada pengembaraan Rasulullah s.a.w sehingga memberikan hikmah dan pelajaran yang sangat berharga bagi umat di zaman baginda s.a.w serta menjadi cermin bagi umat Islam seterusnya:

1. Kaedah pandang dengar yang berlaku antara baginda s.a.w dengan Jibrail a.s telah menggabungkan aspek audio (pendengaran), visual (penglihatan) dan analisis (hati atau minda).

2. Kaedah rihlah (perjalanan) yang berlaku ke atas baginda s.a.w dapat ditaksirkan sebagai suatu proses pembelajaran interaktif.

Selain itu, dalam aspek pengajaran dan pembelajaran ilmu, baik dalam pendidikan umum atau pendidikan Islam sejak dahulu lagi banyak menggunakan pendekatan konvensional. Dalam perspektif pemindahan atau transmisi tradisi ilmu pendidikan Islam, antara pedagogi pengajaran yang digunakan pada zaman Rasulullah s.a.w ialah kaedah kuliah (syarahan), bercerita, soal jawab (dialog), aktiviti menyelidik, lukisan (teknik lakaran), perbincangan (halaqah), perdebatan, demonstrasi, aktiviti permainan (teka-teki) dan pengembaraan (Jaafar \& Tamuri, 2012). Menurut Jaafar \& Tamuri (2012) lagi, terdapat pedagogi lain yang turut digunakan oleh Rasulullah s.a.w iaitu kaedah qudwah hasanah (suri teladan), nasihat dan tamsilan berbentuk kata-kata pendek yang mempunyai pelbagai jenis maksud tersirat. Oleh sebab itu, PdP bagi Pendidikan Islam juga turut memerlukan perubahan sejajar dengan perkembangan teknologi komunikasi abad ke-21. Jika menggunakan hanya satu elemen media sebagai alat PdP Pendidikan Islam sahaja ianya tidak memadai. Pendekatan multimedia dalam pendidikan Islam perlulah bersifat terbuka supaya dapat menghasilkan pengalaman yang menggembirakan sekaligus berupaya mempengaruhi perasaan dan emosi pelajar dalam proses PdP (Zamri \& Mohamed Amin, 2008).

\section{KESIMPULAN}

Sebagai pendidik, guru-guru perlu proaktif dan progresif dalam menentukan teknik pengajaran terutama sekali apabila melibatkan aktiviti pembelajaran di luar bilik darjah. Sesuatu kaedah pengajaran itu pula hendaklah diterapkan dengan cabaran daripada kehidupan sebenar supaya para pelajar dapat meneroka, mengkaji, menginterpretasi di samping menjana pemikiran luar kotak. Pelajarpelajar pada abad ke-21 kini tidak lagi menfokuskan 'konsep suap' daripada guru semata-mata, akan tetapi guru-guru hanyalah sebagai transisi terhadap pengajaran dan pembelajaran, sebagai contohnya menggunakan multimedia bagi menghangatkan suasana PdP. Perkara ini turut disokong oleh Rogers dan Freiberg (1994) dalam penulisannya yang menghuraikan situasi seorang guru secara hakikatnya (Md Ibrahim \& Mohamad Yatim, 2014):

"when teachers as facilitators of learning rather than mere givers of information, students are challenged to think for themselves. When teachers respect students as source of knowledge rather than consumers, students become engaged in the learning process." 
Kenyataan berkenaan jelas memberi mesej terhadap ciri-ciri pengajaran yang berkesan apabila proses kolaborasi antara guru dan pelajar berlaku. Transformasi baharu dalam PdP juga tidak akan terjadi jika pedagogi pengajaran guru masih jumud dan kolot. Banyak kaedah dan keadaan boleh digunakan bagi melaksanakan iklim PdP berpusatkan pelajar yang diterapkan kreativiti dan inovasi tinggi sebagai contohnya pelaksanaan PdP berasaskan multimedia. Pelajar-pelajar di abad ke-21 adalah generasi Z dan Alfa yang sememangnya dikenali sebagai golongan digital native kerana telah terdedah sejak kecil dalam kancah kemodenan rangkaian media. Pelajar-pelajar juga secara semulajadinya mempunyai tarikan yang kuat terhadap pendominasian teknologi digital, gadjet, tablet, teknologi komputer, permainan video, peranti pintar dan internet (Prensky, 2001).

\section{RUJUKAN}

Abdul Majeed, A.B., \& Othman, S. (1998). Cabaran Teknologi Maklumat dan Internet: Agenda Umat Islam. Kuala Lumpur: Institut Kefahaman Islam Malaysia

Abdul Talib, N.S., Awang, M.M., Abdul Ghani, K., \& Yusuff, N.A. (2019). Penggunaan multimedia dalam mata pelajaran sejarah. INSANIAH: Online Journal of Language, Communication, and Humanities, 2(2), 1-13.

Adzhar, H., Karim, A.A., \& Sahrin, M.U. (2017). Pembangunan Instrumen Penerimaan E-Pembelajaran Pelajar Pascasiswazah Menggunakan Analisis Rasch (Development Instrument Acceptance of E-learning Postgraduate Students Using Rasch Analysis). Jurnal Pendidikan Malaysia, 42(2), 1-12.

Aina, M. (2013). Efektifitas Pemanfaatan Multimedia Interaktif Pembelajaran Ipa-Biologi Dalam Meningkatkan Motivasi Belajar Siswa Pria Dan Wanita Smp 19 Kota Jambi. Dalam prosiding Semirata FMIPA Universitas Lampung, 125-130.

Alimom \& Mohd Azlan. (2019). Koswer Pembelajaran Interaktif Dalam Kalangan Pelajar Sekolah Menengah: Penceritaan Khulafa Al-Rasyidin. Journal of Education and Social Sciences, 13(1), 53-60

All, A., Nuñez Castellar, E. P., \& Van Looy, J. (2016). Assessing the effectiveness of digital game-based learning: Best practices. Computers \& Education, 92-93(April), 90-103. https://doi.org/10.1016/j.compedu.2015.10.007

Azhar Stapa, Mohamad Ibrahim \& Amri Yusoff. (2017). Kolaborasi dalam Pendidikan Vokasional: Mewujudkan Pembelajaran Teradun Melalui Teknologi Web 2.0. Journal of ICT in Education (JICTIE), 4, 35-51

Basri, A.A \& Lakulu, M.M. (2018). Kesan Penggunaan Teknik Inkuiri Penemuan Berbanding Tutorial dalam Pembinaan Koswer terhadap Pencapaian Pelajar. Journal of ICT in Education (JICTIE), 5, 40-47

Berita Harian. (2020, April 21). Sedia hadapi kelas maya sesuai normal baharu. Retrieved from https://www.bharian.com.my/berita/nasional/2020/04/679003/sedia-hadapi-kelas-maya-sesuai-normal-baharu

Cooper, G. (1998). Research into cognitive load theory and instructtional design at University of New South Wales (UNSW). Url (last checked 1 December 2006). Retrieved from http://projects.ict.usc.edu/itw/materials/clark/UNSW.htm

Dale, E. (1946). Audio visual methods in teaching. New York: Dryden Press.

Dunn, R. \& Dunn, K. (1978). Teaching Students Through Their Individual Learning Styles: A Practical Approach. Reston. Virginia: Reston Publishing.

Eldy, E.F. \& F. Sulaiman. (2015). E-learning in physics courses: A preliminary findings of students' acceptance. International Journal of Technical Research and Applications, Special Issue, 30, 21-23.

Fitra, A. \& Andrijanto, D. (2013). Pengaruh Media Audiovisual Pembelajaran Servis Forehand Dan Backhand Terhadap Hasil Belajar Servis Pada Permainan Tenis Meja (Studi Pada Siswa Kelas X-1 Dan X-5 Sma Negeri 3 Pamekasan). Jurnal Pendidikan Jasmani, 1(3), 1-10.

Gan, B., Menkhoff, T., \& Smith, R. (2015). Enhancing students' learning process through interactive digital media: New opportunities for collaborative learning. Computers in Human Behavior, 51, 652-663. Retrieved from https://doi.org/10.1016/j.chb.2014.12.048

H. Osman, R. \&. Nasir, M.S. (2011). Karya Al Tawabi’ wa Al Zawabi’ oleh Ibn Shuhayd dan Risalat Al Ghufran oleh AlMa'ari: Satu Adaptasi Daripada Peristiwa Isra' Mi'raj. Dinika Journal of Islamic Studies, Surakarta, Indonesia, 8(1), 1 16.

Hamzah, H., Samuel, J.N., \& Rafidah Kastawi. (2008). Perkembangan kanak-kanak untuk program perguruan pendidikan rendah pengajian empat tahun. Kumpulan Budiman: Subang Jaya

Hj Mak Din, H.A., Zainal Arifin, A.N., \& Mohamed Masrop, N.A. (2014). Permainan Pendidikan Digital: Satu Kajian Awal. Jurnal Sultan Alauddin Sulaiman Sulaiman Shah, 1, 20-27.

Hussin, Z., Siraj, S., Darusalam, G. \& Mohd. Salleh, N.H. (2013). Kajian Model Blended Learning Dalam Jurnal Terpilih: Satu Analisa Kandungan. Jurnal Kurikulum \& Pengajaran Asia Pasifik, 1(2), 20-31.

Ismail, A., Salleh, S., \& Jemali, M. (2016). Analisis Bentuk Didikan Ibu Bapa Bagi Membentuk Sahsiah Cemerlang: Kajian di 
Sekolah Menengah Kebangsaan Pulau Sebang, Alor Gajah, Melaka. Perspektif: Jurnal Sains Sosial Dan Kemanusiaan, 8(2), 1 - 10. Retrieved from http://ejournal.upsi.edu.my/index.php/PERS/article/view/1737

Ismail, I. (1998). Matematik dan masyarakat. Jurnal Akademik Maktab Perguruan Kota Bahru, 6, 30-35.

Ishak, A., Kasa, Z., Selamat, M.H., \& Abu Samah, B. (2009). Perbandingan Pengajaran Berasaskan Multimedia dan Tradisional ke Atas Pencapaian Matematik dan Sikap Matematik di Kalangan Pelajar Berisiko. Jurnal Teknologi Maklumat \& Multimedia, 1(6), 1-11

Isman, A., Aydin, C.H., \& Simsek, I. (2015). The Online Journal of Distance Education and e-Learning. The Online Journal of Distance Learning and E-learning, 3(2), 71.

Jaafar, N. \& Tamuri, A.H. (2012) Hubungan antara efikasi kendiri dengan kualiti guru pendidikan Islam Sekolah Menengah Kebangsaan Malaysia. JIAE: Journal of Islamic and Arabic Education, 5(1), 41-60, ISSN 1985-6236

Jamaludin, H. \& Tasir, Z. (2001). Pengenalan Kepada Multimedia. Kuala Lumpur, Venton Publishing.

Martias, E. (2010) Pentingnya integrasi ICT dalam proses pengajaran dan pembelajaran Pendidikan Islam. Tesis Sarjana Muda. Universiti Pendidikan Sultan Idris

Kaimin, S.K., \& Che Noh, M.A. (2016). Kaedah Media Audio Visual Dalam Pengajaran Dan Pembelajaran Pendidikan Islam. Wacana Pendidikan Islam Siri II, 2016 Institut Latihan Islam Malaysia (ILIM), Bangi, 15-16 November 2016, 1-10

Kassim, Z. \& Abdul Razaq Ahmad, A.R. (2010). E-Pembelajaran: Evolusi Internet Dalampembelajaran Sepanjang Hayat. In proceedings of Regional Conference on Knowledge Integration in ICT 2010, 209-218

Kementerian Pendidikan Malaysia (Unit Komputer dalam Pendidikan). (2001). Pembangunan Pendidikan 2001-2010 Perancangan Bersepadu Kecermelangan Pendidikan. Wilayah Persekutuan Putrajaya.

Koderi, R. (2015). Multimedia Interaktif Dalam Pembelajaran Bahasa Arab. Dalam prosiding Teknologi Pendidikan Universitar Sebelas Maret. 1(1), 102-114

Khairuddin, N.S. \& Mailok, R. (2020). Pembelajaran Berasaskan Permainan Dalam Mata Pelajaran Sejarah Menggunakan Teknik Mnemonik. Journal of ICT in Education (JICTIE), 7(1), 9-15

Mahamod, Z. \& Embi, M.A. (2008). Teknologi Maklumat Dan Komunikasi Dalam Pengajaran Dan Pembelajaran Bahasa Melayu. Shah Alam: Karisma Publication Sdn. Bhd.

Md Ibharim, L.F., \& Mohamad Yatim, M.H. (2014). Kreativiti dan Kemahiran Kanak-Kanak dalam Mereka Bentuk Permainan Digital bagi Tujuan Pembelajaran. Journal of ICT in Education, 1, 87-100.

MdSharif, N. (2012) Kesan penggunaan multimedia dalam kalangan pelajar politeknik yang berbeza gaya kognitif. Tesis Sarjana, Universiti Tun Hussein Onn Malaysia.

Mohid, S.Z., Ramli, R., Abdul Rahman, K., \& Shahabuddin, N.N. (2018). Teknologi Multimedia Dalam Pendidikan Abad 21. In proceedings of the 5th International Research Management \& Innovation Conference (5th IRMIC 2018). Palm Garden Hotel, Putrajaya 7 August 2018, 1-9.

Munusamy, T. \& Mohamad Yatim, M.H. (2017). Keberkesanan Penggunaan Kaedah Frog VLE Terhadap Pencapaian Matematik Sekolah Rendah. Journal of ICT in Education (JICTIE), 4, 66-73.

Prensky, M. (2001). Digital Natives, Digital Immigrants. 9(5), On the Horizon: MCB University Press

Putra, C.A. (2018). Pemanfaatan Teknologi Multimedia untuk Media Instruksional. Journal of ICT in Education (JICTIE), 5 , 1-8

Rahman, S., M. Yasin, R., Salamuddin, N., \& Surat, S. (2014). The Use of Metacognitive Strategies to Develop Research Skills among Postgraduate Students. Asian Social Science, 10(19), 271-274.

Rahman, S., Yasin, R.M., Jusoff, K., Ariffin, S.R., Hayati, N., \& Yusof, S. (2011a). The promotion of metacognitive development in the classroom. Worlds Applied Sciences Journal, 13(1), 95-99

Rogers, C. \& Freiberg, J. (1994). Freedom to Learn. (3rd ed.). New York : Macmillan.

Rosni, A. (2000). Pembangunan perisian multimedia Ekonomi Asas bagi Tajuk "Pengenalan kepada Ekonomi”. Tesis Sarjana Pendidikan, Universiti Kebangsaan Malaysia

Setiawan, A., Suryani, N., \& Asrowi. (2017). Urgensi Pemanfaatan Multimedia pada Pendidikan Agama Islam Jenjang SMK. Teknodika, 15(1), 41-48. Retrieved from https://doi.org/10.20961/teknodika.v15i2.34742

Said., C.S., Umar., I.N., Muniandy., B. \& Desa, S. (2015). Aplikasi Teknologi Multimedia dalam Pembelajaran Sains Biologi: Kesan Terhadap Pelajar Berbeza Tahap Keupayaan Spatial. Journal of ICT in Education (JICTIE), 2, 15-25

Syaibani, A. (1997). Falsafah Pendidikan Islam. Jakarta: Bulan Bintang.

Suparman, R.H. et al. (2016). WLA 104/03 Pengajian Islam. Georgetown, Pulau Pinang: Universiti Terbuka Wawasan

Wanda Wibawanto. (2017). Desain dan Pemrograman Multimedia Pembelajaran Interaktif. Cerdas Ulet Kreatif

Wan A.R. \& Yunus, F. (2017). Cabaran Dalam Meningkatkan Kemahiran Kognitif Kanak-Kanak Prasekolah: Penaksiran Autentik Sebagai Alternatif. Dalam prosiding Persidangan Antarabangsa Sains Sosial \& Kemanusiaan, 1-8.

Wilson, D., Calongne, C., \& Henderson, B. (2015). Gamification Challenges and a Case Study in Online Learning. Internet Learning, 4(2).

Yusopp, A. (2002). Kurikulum Baru Pendidikan Islam Kementerian Pendidikan Malaysia Menghadapi Era Globalisasi. Kuala Lumpur: Dewan Bahasa dan Pustaka.

Zaibon, S. B. (2015). User testing on game usability, mobility, playability, and learning content of mobile game-based learning. Jurnal Teknologi, 77(29), 131-139. 